San Jose State University

SJSU ScholarWorks

Master's Theses

Master's Theses and Graduate Research

1997

\title{
Control-based vs. guidance-based training and displays for automated vertical flight guidance
}

Michael S. Feary

San Jose State University

Follow this and additional works at: https://scholarworks.sjsu.edu/etd_theses

\section{Recommended Citation}

Feary, Michael S., "Control-based vs. guidance-based training and displays for automated vertical flight guidance" (1997). Master's Theses. 1573.

DOI: https://doi.org/10.31979/etd.s4ux-jw8u

https://scholarworks.sjsu.edu/etd_theses/1573

This Thesis is brought to you for free and open access by the Master's Theses and Graduate Research at SJSU ScholarWorks. It has been accepted for inclusion in Master's Theses by an authorized administrator of SJSU ScholarWorks. For more information, please contact scholarworks@sjsu.edu. 


\section{INFORMATION TO USERS}

This manuscript has been reproduced from the microfilm master. UMI films the text directly from the original or copy submitted. Thus, some thesis and dissertation copies are in typewriter face, while others may be from any type of computer printer.

The quality of this reproduction is dependent upon the quality of the copy submitted. Broken or indistinct print, colored or poor quality illustrations and photographs, print bleedthrough, substandard margins, and improper alignment can adversely affect reproduction.

In the unlikely event that the author did not send UMI a complete manuscript and there are missing pages, these will be noted. Also, if unauthorized copyright material had to be removed, a note will indicate the deletion.

Oversize materials (e.g., maps, drawings, charts) are reproduced by sectioning the original, beginning at the upper left-hand corner and continuing from left to right in equal sections with small overlaps. Each original is also photographed in one exposure and is included in reduced form at the back of the book.

Photographs included in the original manuscript have been reproduced xerographically in this copy. Higher quality 6" $\times 9$ " black and white photographic prints are available for any photographs or illustrations appearing in this copy for an additional charge. Contact UMI directly to order.

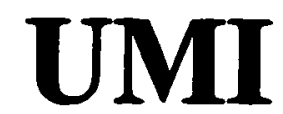

A Bell \& Howell Information Company 
1 


\title{
CONTROL-BASED VS. GUIDANCE-BASED TRAINING AND DISPLAYS FOR AUTOMATED VERTICAL FLIGHT GUIDANCE
}

\author{
A Thesis \\ Presented to \\ The Faculty of the Interdisciplinary Studies Program in Human Factors and Ergonomics \\ San José State University
}

\author{
In Partial Fulfillment \\ of the Requirements for the Degree \\ Master of Science
}

by

Michael S. Feary

December 1997 
ONI Number: 1388191

Copyright 1997 by Feary, Michael Steven

All rights reserved.

UMI Microform 1388191

Copyright 1998, by UMI Company. All rights reserved.

This microform edition is protected against unauthorized copying under Title 17, United States Code.

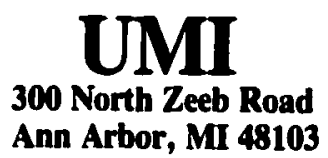


(C) 1997

Michael S. Feary

ALL RIGHTS RESERVED 
APPROVED FOR THE INTERDISCIPLINARY STUDIES PROGRAM OF HUMAN FACTORS AND ERGONOMICS

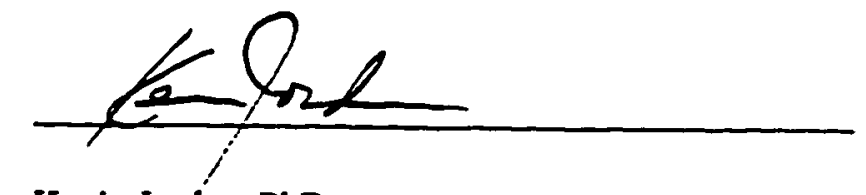

Kevin Jordan, PhD

San José State University

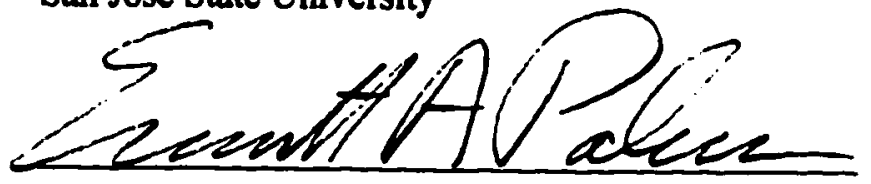

Everett Palmer, PhD

NASA Ames Research Center

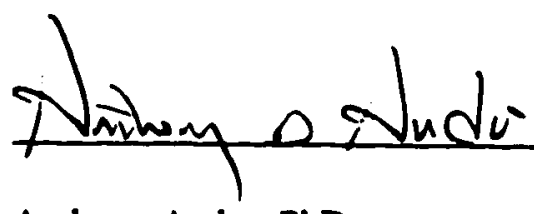

Anthony Andre, $\mathrm{PhD}$

San José State University

APPROVED FOR THE UNIVERSITY

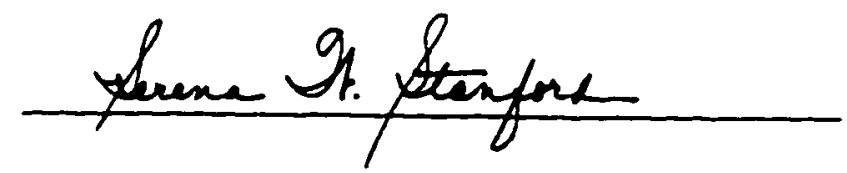




\title{
ABSTRACT \\ CONTROL-BASED VS. GUIDANCE-BASED ANNUNCIATIONS FOR AUTOMATED VERTICAL FLIGHT GUIDANCE \\ by Michael S. Feary
}

\begin{abstract}
Aircraft automation, particularly the automation surrounding vertical navigation, has been cited as an area of training difficulty and a source of confusion during operation. A number of incidents and accidents have been attributed to a lack of crew understanding of the automation. This paper describes an experiment which evaluated the training effectiveness of a new display for automated vertical flight guidance. The study investigated the extension of a formal methodology used to design the vertical guidance logic in the latest generation of autoflight systems. The experiment utilized a training package to teach the vertical guidance portion of the Flight Mode Annunciator (FMA) display, as seen in normal automated operations of the MD-11. The training package was administered to two groups of participants, with one group receiving the current MD-11 display, referred to as the Control-Based FMA, and the other group receiving the new display, referred to as the Guidance-Based FMA. The results showed that participants using the Guidance-Based FMA performed significantly better on some metrics.
\end{abstract}




\section{ACKNOWLEDGMENTS}

This thesis was funded by Cooperative Agreement NCC 2-798 between NASA Ames Research Center and San Jose Staté University. Sincere thanks are owed to my thesis advisors Dr. Everett Palmer, Dr. Kevin Jordan, and Dr. Anthony Andre. This work would not have been possible without Mr. Lance Sherry, Captain Martin Alkin. Additionally, the support of the rest of the E-FMA team, Dr. Peter Polson, and Dr. Daniel McCrobie was invaluable. I would also like to thank my family and friends for their encouragement and support.

This study could not have been conducted without the support of NASA, Federal Express Corporation, Honeywell Inc. Air Transport Systems, and Boeing Commercial Airplane Group. Additionally, a great deal of support was given at Federal Express Corp., particularly by Captain James Ward, Captain Warren Travis, Captain Steve Arena, Captain Dave Hallin, James Brody, and many others, thank you all.

Some of the content of this paper was presented at the Ninth International Symposium of Aviation Psychology. 


\section{TABLE OF CONTENTS}

SECTION

PAGE

INTRODUCTION

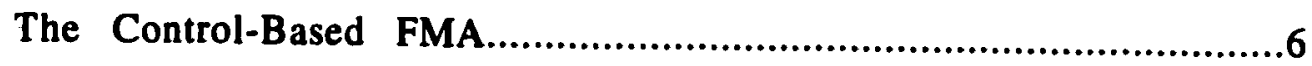

Potential Disadvantages of the Control-Based FMA.............................8

Operational Relevance.................................................8

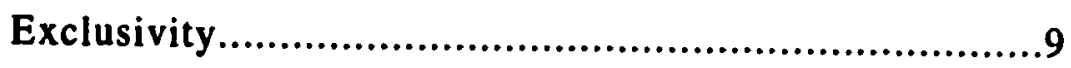

Display-System Design Compatibility................................10

Display Discrimination................................................12

The Guidance-Based FMA..........................................................12

Potential Advantages of the Guidance-Based FMA...........................15

Operational Relevance...............................................15

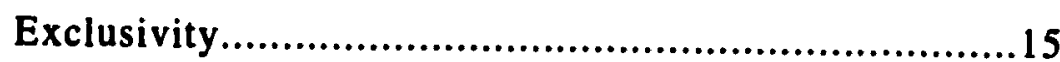

Display-System Design Compatibility...............................19

Display Discrimination................................................19

Potential Disadvantages of the Guidance-Based FMA.......................19

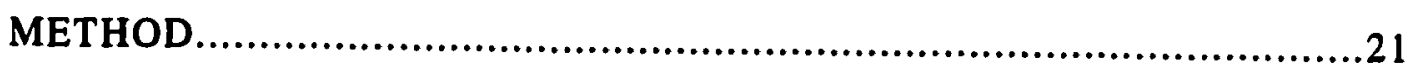

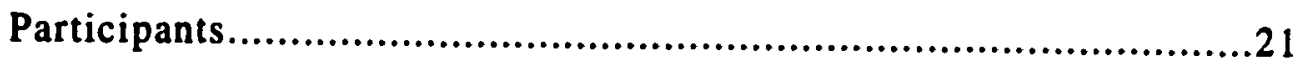

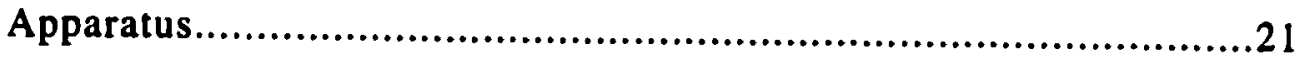

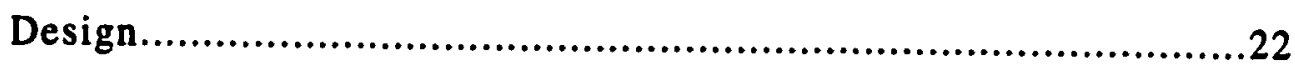

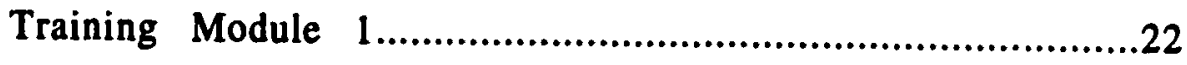

Training Module 2........................................................24

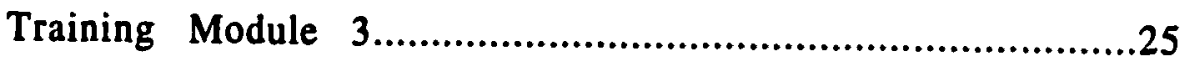

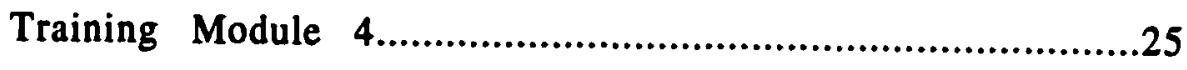

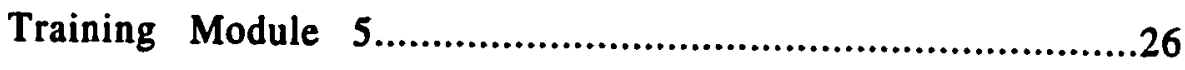


Test Module.............................................................26

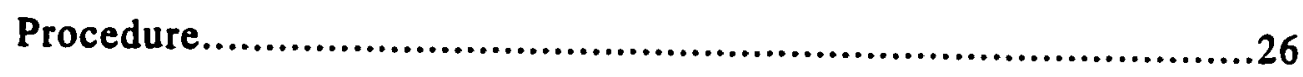

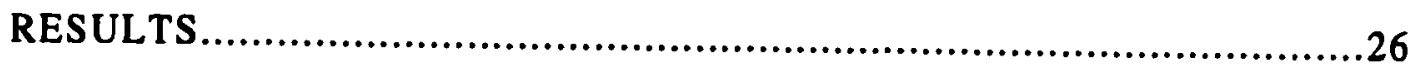

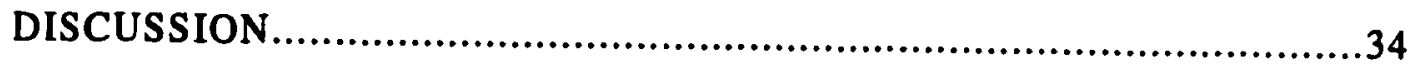

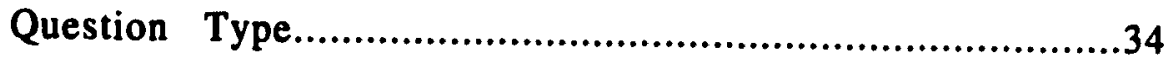

Annunciation Differences.......................................................35

Label-Following Heuristic..................................................36

Training Material Development...............................................37

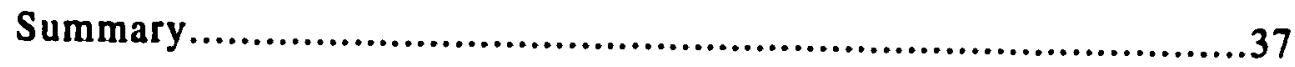

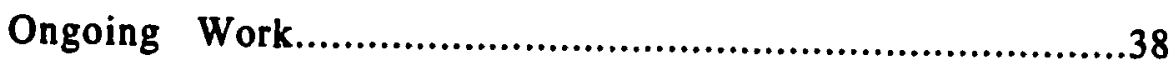

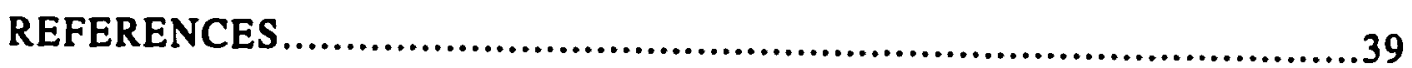

APPENDIX A Experiment Introduction Sheet..............................................40

APPENDIX B Human Subjects Approval Form.............................................41 


\section{LIST OF FIGURES}

FIGURE

PAGE

1. The Primary Flight Display of the MD-11............................................5

2. The Current MD-11 (Control-Based) FMA............................................7

3. Comparison of LATE DESCENT and DESCENT OVERSPEED Annunciations......11

4. Design transition from autoflight system to the Control-Based FMA...................13

5. Design transition from autoflight system to the Guidance-Based FMA..................14

6. The Guidance-Based FMA........................................................

7. Control-Based versus Guidance-Based Flight Mode Annunciations....................17

8. Comparison of C-FMA and G-FMA for LD and PDO Annunciations...................18

9. Comparison of PATH DESCENT Annunciations....................................20

10. Training Material Example Slides....................................................23

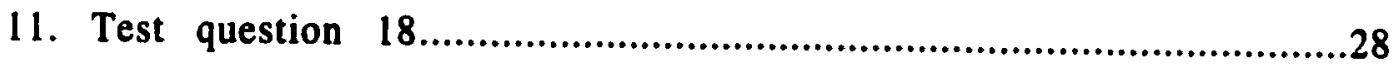

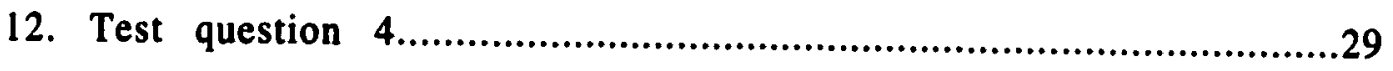

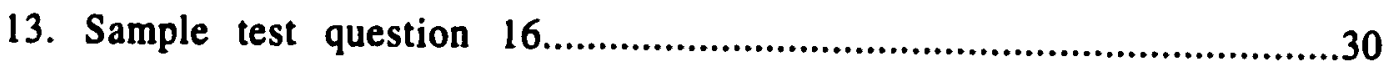

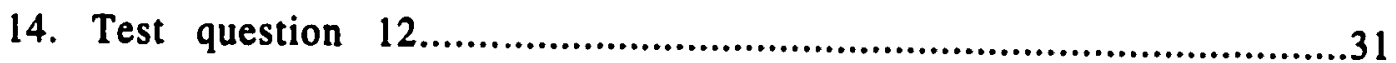

15. 2 way interaction between question type and FMA condition...........................33 


\section{LIST OF TABLES}

TABLE

PAGE

1. Matrix of Response Variable Conditions..................................................27 
Control-Based vs. Guidance-Based Annunciations for Automated Vertical Flight Guidance Michael S. Feary

San José State University

\section{Running Head: FLIGHT MODE ANNUNCIATION FOR VERTICAL GUIDANCE}

\section{Footnote}

Correspondence concerning this paper should be addressed to mfeary@mail.arc.nasa.gov or the SJSU Department of Engineering at: http://www-engr.sjsu.edu/-svej/ 


\begin{abstract}
Aircraft automation, particularly the automation surrounding vertical navigation, has been cited as an area of training difficulty and a source of confusion during operation. A number of incidents and accidents have been attributed to a lack of crew understanding of the automation. This paper describes an experiment which evaluated the training effectiveness of a new display for automated vertical flight guidance. The study investigated the extension of a formal methodology used to design the vertical guidance logic in the latest generation of autoflight systems. The experiment utilized a training package to teach the vertical guidance portion of the Flight Mode Annunciator (FMA) display, as seen in normal automated operations of the MD-11. The training package was administered to two groups of participants, with one group receiving the current MD-11 display, referred to as the Control-Based FMA, and the other group receiving the new display, referred to as the Guidance-Based FMA. The results showed that participants using the Guidance-Based FMA performed significantly better on some metrics.
\end{abstract}


Control-Based vs. Guidance-Based Annunciations

for Automated Vertical Flight Guidance

Automation is being used increasingly in complex systems. In many cases, the introduction of automation has led to more efficient and safe operation of these complex systems; however, the changing role of the human operator has introduced new challenges. These new challenges are especially apparent in systems which are fully automated some of the time, but still require some human intervention. An example of this is aircraft automation, for which pilots remain a necessity for safe operation. The role of a pilot has changed in modern aircraft, with an increase in tasks involving monitoring and interacting with the aircraft's automated systems. This paper details a proposed display change to reflect the changing task of the pilot.

Aircraft automation, for the purposes of this paper, will be limited to the "up and away" vertical portion of the autopilot system, the autothrottle system, and the Flight Management System (FMS). "Up and away" refers to all flight modes except takeoff, approach, and landing. Additionally, this paper will not cover modes used for abnormal operations, such as engine failures, or automation used in special circumstances, such as speed envelope protection.

The vertical portion of the autopilot consists of five modes of operation: speed on Pitch, Vertical Speed, Flight Path Angle (Vertical Speed and Flight Path Angle hold a fixed rate of ascent or descent), altitude Hold, and control to the FMS computed Optimum Descent Path. The autothrottle, as the name implies, controls the different power settings required for the different automated tasks in flight. The autothrottle system consists of three modes of operation: speed on Thrust, Climb Thrust, and Idle.

The vertical portion of Flight Management System is used to calculate the most efficient trajectory for the aircraft, to select the autopilot and autothrottle modes, and the speedaltitude targets. Early autopilot systems could only handle one or two functions, but with 
the addition of the FMS, the new "autoflight systems" have gained considerable complexity. Sherry et al. (1997) identified 16 modes and 289 rules for selecting the PitchThrust control modes and Speed-Altitude targets in a current version of MD-11 vertical guidance logic. This complexity requires pilot knowledge of the different modes, or "behaviors" of the system. Aircraft "behavior" refers to the method the aircraft automation uses to achieve the objectives of the system.

"Mode management" difficulties in aircraft automation have been well documented as incidents and accidents, errors observed in operation, and difficulty in training (FAA HFT Report, 1996). A common finding reported in the literature cited by the FAA Human Factors Team is that pilots are not trained on how to use and understand the automation displays. The primary autoflight system status display is the Flight Mode Annunciator (FMA). The FMA has been the focus of previous aviation automation research (Hutchins, 1996; Sarter \& Woods, 1993).

Additionally, significant changes in the air traffic environment are taking place which will require further changes in the pilot's task. Examples of these changes can be seen with the introduction of new Communications Navigation and Surveillance (CNS) technologies, such as datalink capabilities, Global Positioning System (GPS), and Automatic Dependent Surveillance-B (ADS-B). These technologies, and their accompanying new procedures, such as FMS Arrivals, require use of the FMS, and consequently require greater knowledge of the vertical guidance. This study was performed to examine pilots' knowledge and operation of automated vertical guidance, and the strategic use of the FMS.

This study chose the Boeing/McDonnell Douglas MD-11 as an example of the latest generation of autoflight systems. The FMA for the MD-11 is located at the top of the Primary Flight Display (Figure 1). The Primary Flight Display groups all the short term flight information, such as airspeed, heading, altitude, attitude, etc. in one place, to provide quick access to tactical (i.e. short term) flight information. 


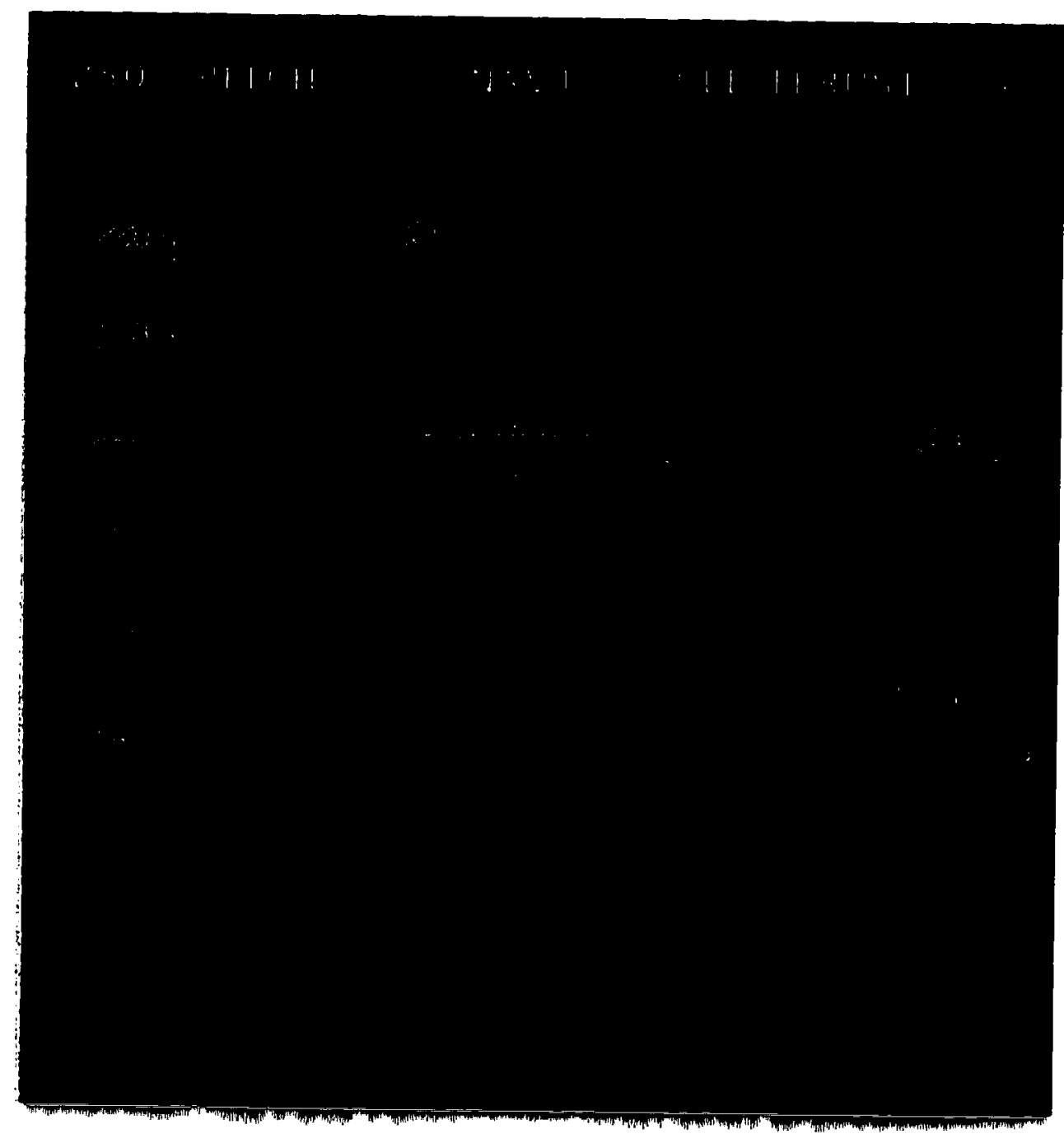

Figure 1. The Primary Flight Display of a Boeing/McDonnell Douglas MD-11. The FMA can be seen as the annunciations at the top of the PFD. 
The Control-Based (MD-11) FMA

The name "Control-Based" FMA refers to the FMA providing information about how the axes of the aircraft are being controlled by the autoflight system pitch and thrust control modes to achieve the targets. The Control-Based FMA consists of a speed target, a speed mode, an altitude mode, and an altitude target (Figure 2). These annunciations are the output of the 289 rules used for vertical guidance decision making in the FMS. One way to describe the Control-Based FMA shown in Figure 2 is to say that "the speed target of ' 355 ' knots is being controlled to by 'Pitch', with thrust controlled to 'Climb Thrust' for an altitude target of Flight Level '230'." The "NAV1" annunciation seen in the center column of the FMA is the lateral mode annunciation, and will not be addressed in this paper.

The speed target is the speed that the aircraft is trying to achieve. The speed mode refers to how the autopilot or autothrottle will control the speed of the aircraft to achieve the speed target. There are two methods for an aircraft to maintain speed. The first method uses the autopilot to control to the speed target by varying the pitch of the aircraft. This is commonly referred to as "speed on pitch". The second method uses the autothrottle to vary thrust to maintain the speed target. This is commonly referred to as "speed on thrust".

The altitude mode annunciation describes how the altitude target will be achieved. The altitude mode reflects whether the autopilot is tracking an altitude, such as maintaining a constant altitude or path, or the autothrottle is tracking a constant thrust setting. Only certain combinations of speed and altitude mode annunciations can appear together. To illustrate using the climb example given above, the altitude mode annunciation CLB THRUST will only appear with the PITCH speed mode. The speed mode THRUST and the altitude mode CLB THRUST will never be seen simultaneously because the autopilot and autothrottle only operate in certain combinations. If speed is controlled by thrust, then the autopilot must control the altitude of the airplane with pitch. If speed is controlled by 


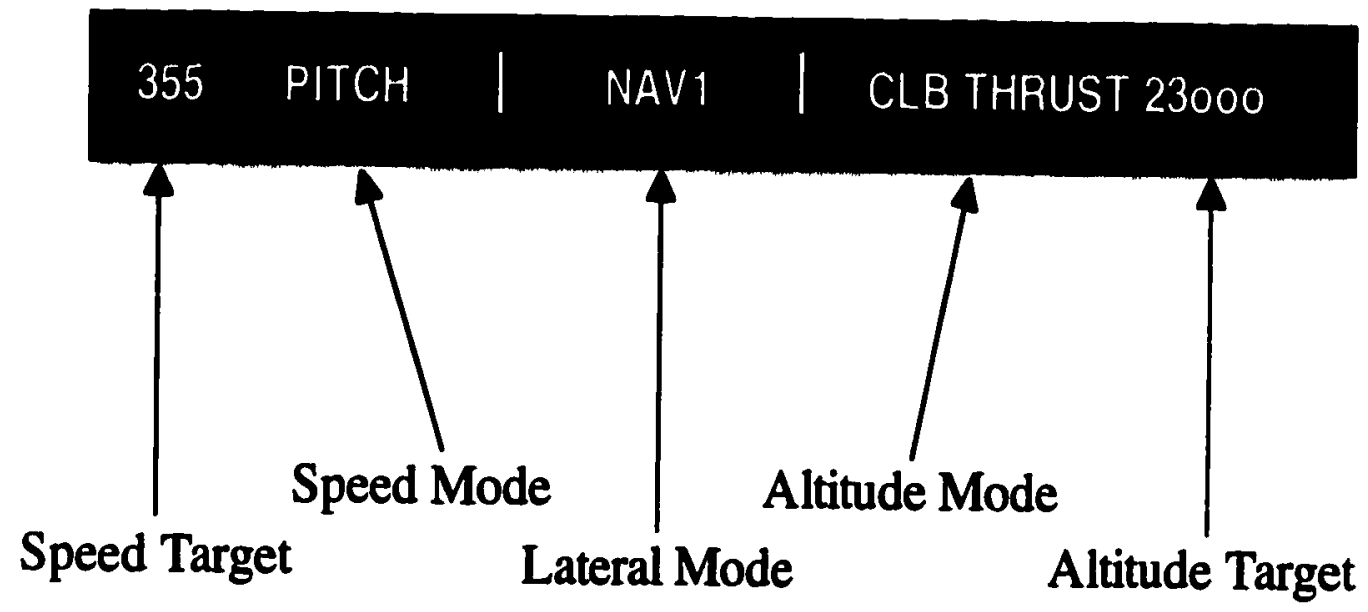

Figure 2. The Current MD-11 (Control-Based) FMA 
the pitch of the airplane, then the thrust setting is climb power for climb, or idle power for descent.

\section{Potential Disadvantages of the Control-Based FMA}

The Control-Based FMA in the MD-11 is an improvement over previous generations of FMAs. However, there are several proposals to improve it further. The modifications used for this experiment were specifically intended to improve four different qualities of the system annunciation. These are referred to as operational relevance, exclusivity, displaysystem design compatibility, and display discrimination.

Operational Relevance. Operational Relevance refers to using annunciations which are operationally meaningful to the pilot. The FMA should be used by the pilot to confirm that the objectives of the autoflight system match his or her objectives.

The Control-Based FMA uses abbreviations and terms that need to be translated to represent the task. To explain, there are a number of different ways to mentally represent and manipulate the energy of the aircraft. The Control-Based FMA uses the representation of Pitch and Thrust control modes described earlier. Previous research (Hutchins, 1996) found that not all pilots agree with the speed on pitch or speed on thrust view of flying the airplane. This can be heard in the descriptions that pilots use when discussing the different automated tasks. For example, pilots do not describe an autoflight climb as using PITCH and CLB THRUST, and Air Traffic Controllers do not ask pilots to "PITCH and CLB THRUST to Flight Level 230."

The Control-Based FMA does not explicitly describe the "intent" of the FMS. The intent can be inferred from the Control-Based FMA, but only when the annunciations are exclusive of each other, which will be described in the next section. Another way of describing this is in terms of what is "operationally meaningful" to the pilot.

The result of an annunciation that needs to be translated to be operationally meaningful is more cognitive processing, the equivalent of more work for the pilot. The amount of this 
additional workload decreases as the pilot becomes more expert and the translation becomes automatic.

Exclusivity. Exclusivity refers to using a unique name for each operationally meaningful automation behavior. Non-exclusive names can cause confusion in interpreting the behavior of the automation. For example, aircraft with Flight Management Systems calculate a descent path which is the most efficient way to descend the aircraft. This is referred to as the "optimum descent path". In the MD-11, the LATE DESCENT behavior was developed to cope with the situation that arises when the aircraft is forced to fly beyond the optimum descent path. The view of the pilots on the design team for this situation was that the airplane will continue to have excessive energy until it has returned to the optimum descent path. The goal of the automation is to return to the optimum descent path as quickly as possible once the airplane is allowed to descend. This objective is achieved by descending with speed on pitch and the throttles at idle, to a faster speed target (approximately 10 knots below the maximum speed limit).

This contrasts with another behavior, PATH DESCENT OVERSPEED, which was designed to handle situations in which the initial calculation of the optimum descent path resulted in a path that was too steep. The optimum descent path naturally shallows out in the later stages of the descent, so the objective of this behavior is to hold the speed of the airplane constant, and wait for the optimum descent path to "catch up" with the airplane. This behavior is also achieved with speed on pitch and idle thrust, but it uses the optimum descent path speed target, which is slower than the LATE DESCENT speed target.

The differences between these behaviors have operational meaning for pilots. To illustrate, the higher speed target in LATE DESCENT may take some pilots by surprise if they are not aware of the objective of trying to return to the optimum descent path as quickly as possible. Additionally, because LATE DESCENT reflects the aircraft position beyond the path, the pilot should be aware that the possibility of not making a waypoint 
altitude restriction has increased. Another difference is that PATH DESCENT OVERSPEED is an automatic speed protection behavior which is not pilot initiated, unlike the LATE DESCENT behavior. A difficulty is that the Control-Based FMA uses the same annunciation (Pitch and Idle thrust) for these different behaviors. Figure 3 compares these two Control-Based FMA annunciations.

The lack of difference in annunciation results in a system which may appear to be unpredictable to the pilot. If a system is unpredictable, evaluation and acquisition of knowledge about the system, becomes very difficult. Evaluation of the system becomes difficult because the pilot is unable to determine the "intent" of the automation or diagnose a mismatch between his/her goals and those of the automation. Acquisition of rules about the behavior of the automation is made difficult because it is unclear which information should be retained.

Display-System Design Compatibility. Display-system design compatibility refers to using the system model as the source and structure of the information to be displayed. In the MD-11, the word "PROF" is used to denote the behaviors and targets calculated by the FMS. This is represented on the FMA by the use of magenta colored characters. When PROF is not engaged, the annunciations are represented in white.

Despite the color convention to signal the automation use, the current MD-11 FMA also uses PROF as a label to describe the optimum path descent behavior. This format disagrees with the display-system design compatibility guideline.

The lack of display-system design compatibility results in exceptions to the rules needed to understand and operate the system. Each exception requires the pilot to learn at least one more rule on how to interpret the display. It does not take many of these extra rules to make systems with this much complexity difficult to learn. 


\section{LATE DESCENT Annunciation}

\section{PITCH | NAV1 | IDLE 23000}

PATH DESCENT OVERSPEED

Annunciation

\section{PITCH | NAV1 | IDLE 23000}

Figure 3. Comparison of LATE DESCENT and PATH DESCENT OVERSPEED

Annunciations 
Display Discrimination. The display discrimination guideline refers to optimizing the differences between the different annunciations. Since only capital letters are used in the current FMA, and color is used to differentiate between the level of automation being used, word length becomes a major characteristic of discrimination between modes. The Control-Based FMA uses descriptions which tend to be about five characters in length, which does not allow for much discrimination between the different annunciations.

In the design of the MD-11 vertical guidance logic, the autopilot and autothrottle system components were grouped together into "behaviors" which were intended to provide a specific method for dealing with any situation that the automation would encounter. These behaviors were then translated again to provide the pilot a coherent view of how the automation was controlling the aircraft. Figure 4 reflects the transition of the flight guidance system to the way the design team conceptualized and referred to the flight guidance system modes, and finally to how the flight guidance modes are annunciated.

\section{The Guidance-Based EMA}

This study proposed a "Guidance-Based" FMA to help improve pilot recognition and understanding of the automation. The Guidance-Based FMA provides information on the tactical mode used by the FMS for the current mission behavior. It was designed to improve the recognition and understanding of the "objectives and behaviors" of automated systems through a formal methodology, referred to as the Operational Procedure Methodology (Sherry, 1995; Sherry et al., 1995; Sherry et al., 1997). The Operational Procedure Methodology utilizes the input of the designers as rule based logic to form the foundation for the concepts that need to trained. The name "Guidance-Based FMA" refers to a display that annunciates the 13 top level behaviors that group the 289 different scenarios which are specified in the logic of the FMS vertical guidance. The 13 different top level "behaviors" were identified by the operators and designers to reflect the current intention of the aircraft automation. Figure 5 illustrates the process used for deriving the 


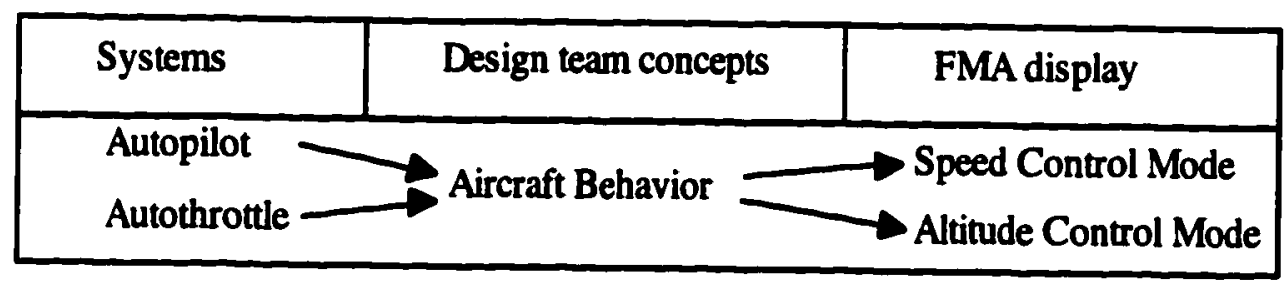

Figure 4. Design transition from autoflight system to the Control-Based FMA 


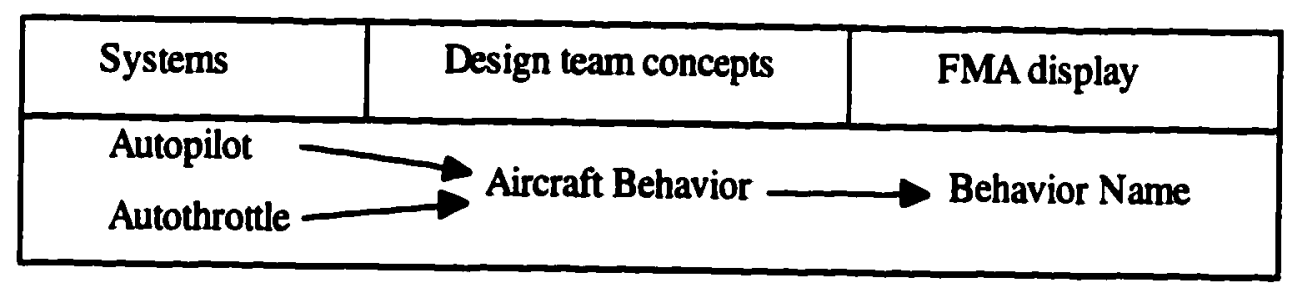

Figure 5. Design transition from the autoflight system to the Guidance-Based FMA. 
names for the Guidance-Based FMA. The guidance task can be described as choosing a method of control (i.e. behavior) from a number of alternatives.

The Guidance-Based FMA took advantage of the meaningful names that the operators and designers gave to the different behaviors and replaced the speed-altitude control mode combinations with these behavior names (Figure 6). A way to describe the GuidanceBased FMA shown in Figure 6 is to say that the airplane is in a "' 355 ' knot 'Climb' to 'FL230'." The "NAV1" lateral annunciation has been moved to the left to accommodate the change to the new FMA.

\section{Potential Advantages of the Guidance-Based FMA}

Using the same four criteria mentioned above, the Guidance-Based FMA shows improvements in operational relevance, exclusivity, display-system design compatibility, and display discrimination.

Operational Relevance. A comparison of the actual names used in the Control-Based and Guidance-Based FMAs are shown in the two columns of Figure 7. The GuidanceBased FMA achieves improved operational relevance in three ways. First, by using an integrated description it more closely matches the pilot's task. Second, using the behavior names makes the task of predicting the next autoflight transition easier by focusing more on the objective of the system, and less on the method used by the autopilot and autothrottle for achieving the current targets. Last, the Guidance-Based FMA relies on descriptions, not combinations of control actions. Since not all combinations of actions are possible, there is less information to learn.

Exclusivity. Figure 8 shows how the Guidance-Based FMA achieves exclusivity. As described above, the situations and behaviors for LATE DESCENT and PATH DESCENT OVERSPEED are different, but the displays for the current Control-Based FMA seen in the left column of Figure 8 are almost identical. The Guidance-Based FMA, seen in the right 


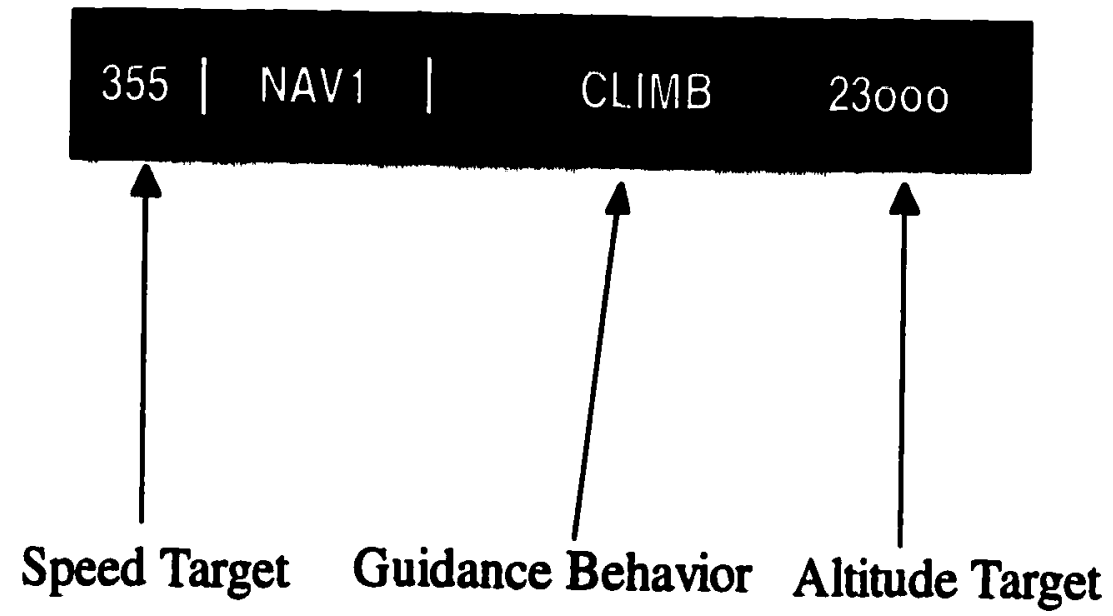

Figure 6. The Guidance-Based FMA 


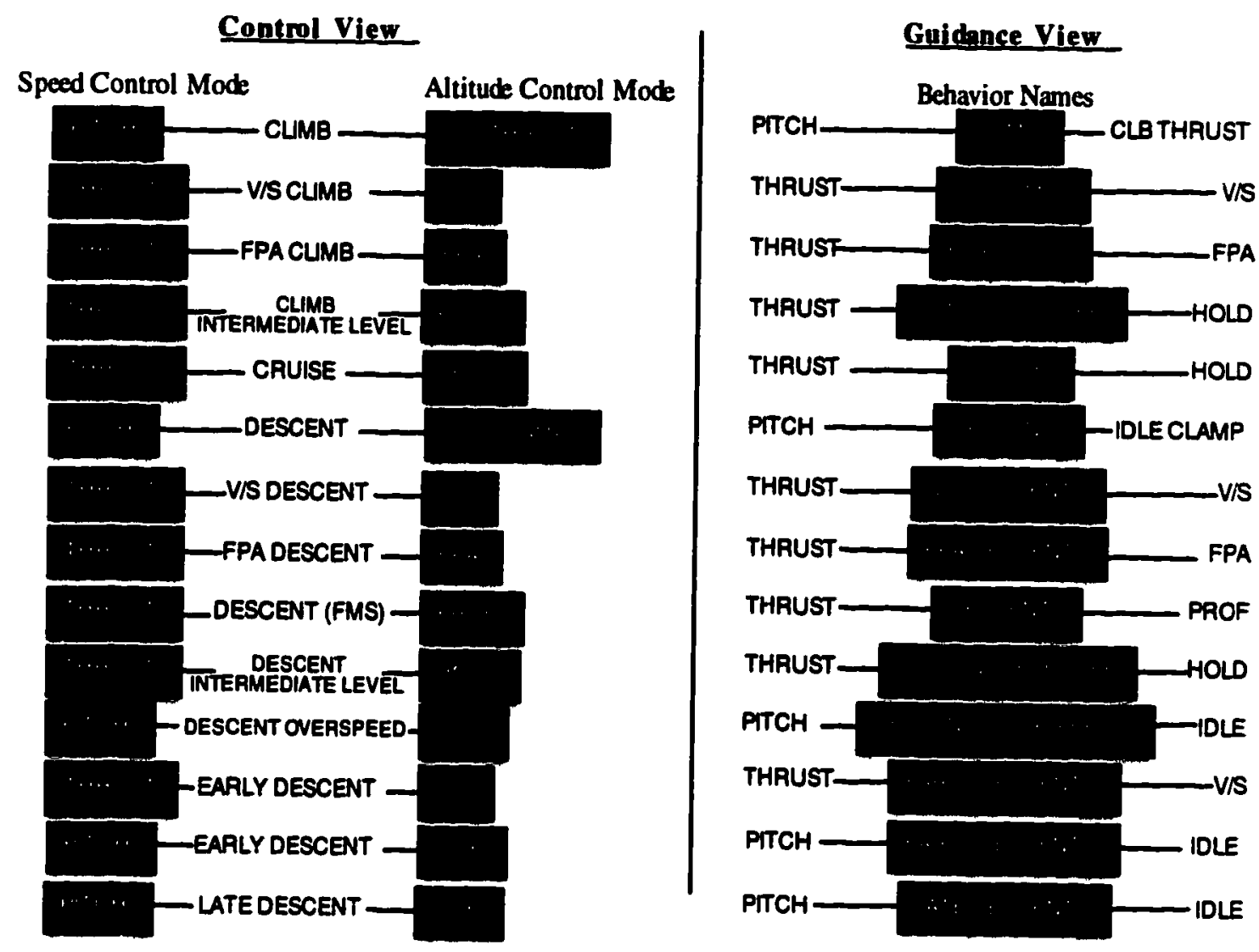

Figure 7. Control-Based versus Guidance-Based Flight Mode Annunciations

(Modes which are derived from the FMS are depicted on the FMA as magenta text while GCP selected modes are depicted on the FMA as white text.) 
Control-Based FMA

Guidance-Based FMA
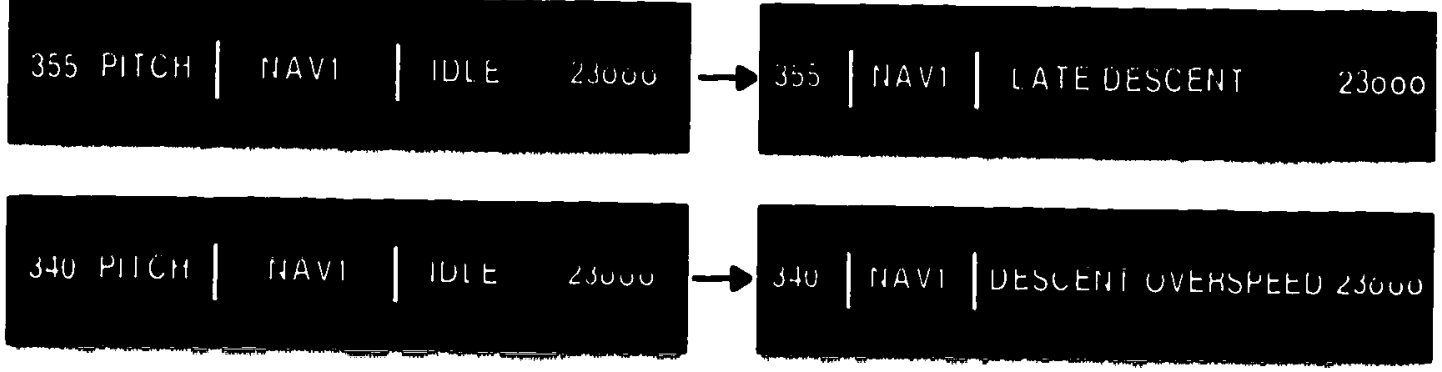

Figure 8. Comparison of Control-Based FMA and Guidance-Based FMA for LATE DESCENT and PATH DESCENT OVERSPEED 
column of Figure 8, provides a unique and meaningful label for these two different situations.

Display-System Design Compatibility. The Guidance-Based FMA uses the vertical guidance names and structures as developed by the operators and designers. The MD-11 refers to using the FMS for aircraft control with the word PROF. As such, PROF refers to a top level description of a number of different modes. These modes are entered by pushing a button on the Glareshield Control Panel labeled "PROF". Following the structure of the vertical guidance design, the FMA annunciation for the lower level mode of following the FMS optimum descent path "PROF", on the Control-Based FMA is inconsistent (Figure 9). The design of the Guidance-Based FMA adheres to the structure of the system by using an annunciation that refers to the optimum path descent.

Display Discrimination. More information can be derived at a glance from the Guidance-Based FMA than from the Control-Based FMA, because the Guidance-Based labels are shorter for frequently used behaviors, and longer for less frequently used behaviors. This convention agrees with Zipf's law for using command languages for human-computer interaction (Ellis \& Hitchcock, 1986). Notice that CLIMB, CRUISE and DESCENT in the Guidance-Based FMA are thought of as the most frequently used methods of flying the airplane, and that the other behaviors use names which are longer than these, providing better discrimination for modes which are infrequently used. Potential Disadvantages of the Gujdance-Based FMA

One concern about the Guidance-Based FMA is the elimination of the speed or altitude control mode annunciations. This concern will not be resolved with this experiment; however, there are some responses to this concern. First, the speed mode annunciation does not give accurate control information all of the time. In fact, the speed mode annunciation is an approximation of the most used form of speed control. An 


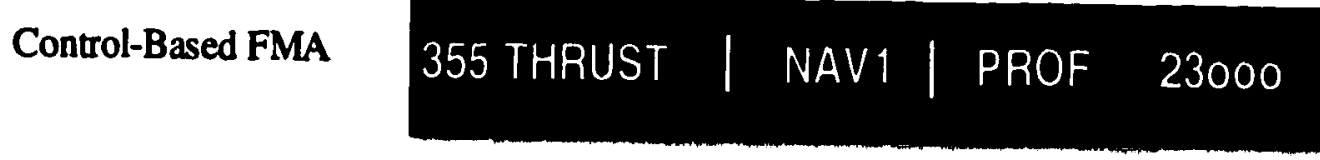

\section{\begin{tabular}{l|l|l|ll} 
Guidance-Based FMA & 355 & NAV1 & DESCENT & 23000
\end{tabular}}

Figure 9. Comparison of Control-Based FMA and Guidance-Based FMA for PATH DESCENT 
example of this is LEVEL CHANGE, which uses a complicated set of algorithms to make a smooth transition from level flight to a climb or descent. Therefore, although the FMA is annunciating speed on pitch, the airplane is not always using pitch to control the speed. Second, the speed control mode causes the most difficulty during automated descents, because the pilot must decide when to use the drag devices, and how that will effect the behavior of the aircraft. Looking at the behaviors listed in Figure 7, there are only two excess energy guidance behaviors: LATE DESCENT and DESCENT PATH OVERSPEED.

A second argument is that the combination of speed and altitude control modes has resulted in a set of displays that, without training on the design of the system, are not recognized by a large number of pilots currently using the system. The Guidance-Based FMA asks pilots to remember how speed is controlled for the different behaviors, if it is necessary, but the hypothesized benefits of simplification outweigh the risk of possibly increasing memory load for one or two behaviors. A behavior based display should use names which are descriptive enough that a pilot should agree with the system design. The pilot should not be required to memorize all the different behaviors.

\section{Method}

\section{Participants}

Thirty-four current DC-10 pilots and instructors with no previous commercial glass cockpit experience volunteered to participate in this study. These volunteers were recruited through the electronic mail system of a large MD-1l operator. Each pilot was presented with either the Control-Based or the Guidance-Based display condition.

\section{Apparatus}

The platform used to evaluate the displays was a computer-based training package designed to train and test recognition of the Flight Mode Annunciations seen in normal 
operations of the MD-11. The training system was configured to collect data from each participant.

Design

The experiment consisted of comparing the Control-Based and the Guidance-Based annunciations presented in the two columns of Figure 7. The training material defined each item of information on the FMA, but only taught the Vertical Guidance portions of the FMA in detail. The organization of the material in the training package consisted of five training modules and a test module. This information was presented in an interactive slide show format. This format required all participants to view a set of required slides, but participants who answered questions incorrectly would see more slides than a participant who answered every question correctly. An example of this training material can be seen in Figure 10.

Training Module 1: GCP Operations. The first training module provided a framework for understanding the latter modules. The module introduced nine target and control mode combinations. These combinations are referred to as "GCP Operations," because they are directly selected by the pilot through the Glareshield Control Panel (GCP). The GCP Operations are represented as white annunciations on the FMA. At the end of the module the participants were given five quiz questions to test their knowledge of the new concepts.

The annunciations for the Control-Based FMA consisted of the GCP speed target, the "PITCH" and "THRUST" speed control modes, the "CLB THRUST, DLE CLAMP, V/S, and FPA" altitude control modes, and the GCP altitude target. Participants were required to view a set of 73 slides, but it was possible for a participant to go through more than this if incorrect selections were made. The total number of slides that any participant could see for the Control-Based FMA version of Module I was 111.

The training material for the "Guidance-Based" FMA was designed to be equivalent to the training material for the Control-Based FMA, but the elimination of one annunciation 


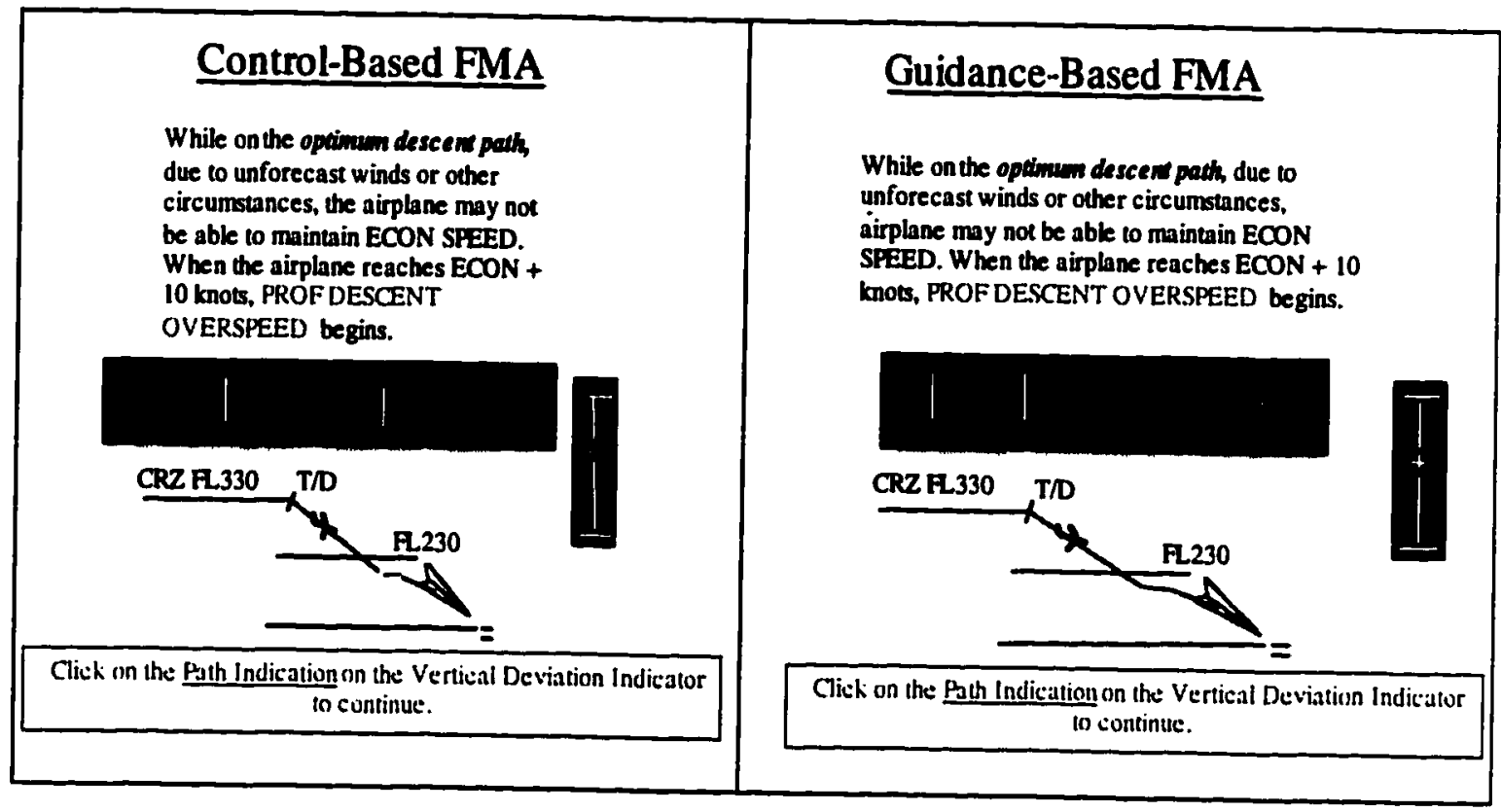

Figure 10. Example Slides from Training Material 
field resulted in a slight reduction in the number of slides to cover the same material. The annunciations for the GCP speed and altitude target remained the same as the Control-Based FMA, but the speed and altitude mode combinations were replaced with the following Guidance-Based annunciations: CLIMB, V/S CLIMB, FPA CLIMB, CRUISE, DESCENT, V/S DESCENT, and FPA DESCENT. This display modification produced 61 required slides, with a total of 99 slides accessible for the Guidance-Based FMA version of the training material.

The format for the training material consisted of a paragraph describing each behavior, and a sentence describing the FMA. For example, the concept of maintaining speed with pitch was described in a paragraph within the description of Level Change Climb behavior. The Level Change Climb behavior for the Control-Based FMA was then described as " 300 knots speed on pitch, with climb thrust to Flight Level 230." This format was used for the all of the training modules.

Training Module 2: PROF Operations. The second module introduced the concept of "PROF Operations" and seven overview "PROF" behaviors and annunciations. PROF operations refer to the most automated method of airplane control, in which the targets and mode combinations are indirectly chosen by the pilot. At the end of this module six questions were presented to the participants. Only five of these questions were scored; the sixth question was considered too difficult for the type of training, but used to assess deeper understanding of the concepts involved with the module.

The annunciations covered in the Control-Based FMA version of Module 2 consisted of the FMS ECON speed target, PROF "PITCH" and PROF "THRUST" speed control modes, PROF "CLB THRUST, HOLD, and DESCENT", and the Cruise Flight Level Altitude Target. The "PROF Operations" are represented by magenta annunciations. There were 61 required slides and 83 total slides in the Control-Based version of Module 2. 
The Guidance-Based FMA version of the second module described the same behaviors, however it used CLIMB, CRUISE and DESCENT as the behavior names. There were 55 required slides and 78 total slides in the Guidance-Based version of Module 2.

Training Module 3: CLIMBDESCENT INTERMEDIATE LEVEL, and CRUISE. The third module covered three PROF Cruise behaviors in more detail. These are referred to as Climb Intermediate Level, Cruise (Long Range), and Descent Intermediate Level. The Control-Based FMA used the same annunciation for all three of these behaviors, but the Guidance-Based FMA used "CLIMB INT LVL, CRUISE, and DESCENT INT LVL" as the annunciations of the different behaviors. Four quiz questions were given to the participants at the end of this module. There were 65 total slides in the Control-Based and Guidance-Based versions of Module 3. The shortest path through either version was 44 slides.

Training Module 4: EARLY DESCENT and LATE DESCENT. The fourth module covered two of the PROF DESCENT behaviors, EARLY DESCENT and LATE DESCENT, and the LATE DESCENT speed target.

The EARLY DESCENT behavior is used when the airplane is required to descend before reaching the optimum descent path. The Control-Based FMA annunciation for EARLY DESCENT is "THRUST" and "V/S". The annunciation for the Guidance-Based FMA is "EARLY DESCENT".

The LATE DESCENT behavior is used when the airplane is required to descend after passing the optimum descent path. The annunciation for the Control-Based FMA is "PITCH and IDLE". The annunciation for the Guidance-Based FMA is "LATE DESCENT". The differences between these two annunciations are depicted in Figure 7.

Four quiz questions were given at the end of this module. There were 23 required slides and 39 total slides in both the Control-Based and Guidance-Based versions of this module. 
Training Module 5: PATH DESCENT OVERSPEED. The fifth module described the last PROF behavior, PATH DESCENT OVERSPEED. PATH DESCENT OVERSPEED, as described above, is used if the airplane is on the optimum descent path but faster than the ECON speed target. There were 12 required slides and 16 total slides in both versions of Module 5. The reduction in the number of display items resulted in about $5 \%$ less training material for the Guidance-Based FMA condition.

Test Module. The final module consisted of 20 test questions. The test was designed so that the only difference between the questions was the FMA condition. There were four categories of questions: "Given an FMA, select the present situation description", "Given the present situation, select an FMA", "Given an FMA, select a future situation", and "Given a future situation, select an FMA". Table 1 shows the matrix of the different question types. Examples of these types of questions are shown in Figures 11 through 14. Procedure

The experiment was conducted in the computer based training room at the training center of a major airline. The participants were given an introduction sheet (Appendix A). The participants were also given three verbal instructions by the experimenter. First, the participants confirmed that they had not previously flown a glass cockpit aircraft. Second, the participants were told that timing data was being collected. Third, the participants were informed that the average time to complete the package was $1^{1 / 2}-2$ hours, but they should feel free to take as much time and as many breaks as they wanted, and review anything they wanted, as long as they informed the experimenter of their activities. There were no reported difficulties with this procedure.

\section{Results}

To review, this study evaluated the training effectiveness of a new display for automated vertical flight guidance. This was measured through a between-subjects experiment, with 34 participants randomly assigned to either the Control-Based FMA or 
Table 1.

Response Variable Conditions Matrix

\begin{tabular}{lll}
\hline Temporal Status & \multicolumn{2}{c}{ Presentation Order } \\
\cline { 2 - 3 } Surrent Situation & $\begin{array}{l}\text { Given the present situation, } \\
\text { select an FMA. }\end{array}$ & $\begin{array}{l}\text { Given an FMA, select } \\
\text { the present situation } \\
\text { description. }\end{array}$ \\
Future Situation & $\begin{array}{l}\text { Given a future situation, } \\
\text { select an FMA. }\end{array}$ & $\begin{array}{l}\text { Given an FMA, select } \\
\text { the future situation } \\
\text { description. }\end{array}$ \\
\hline
\end{tabular}




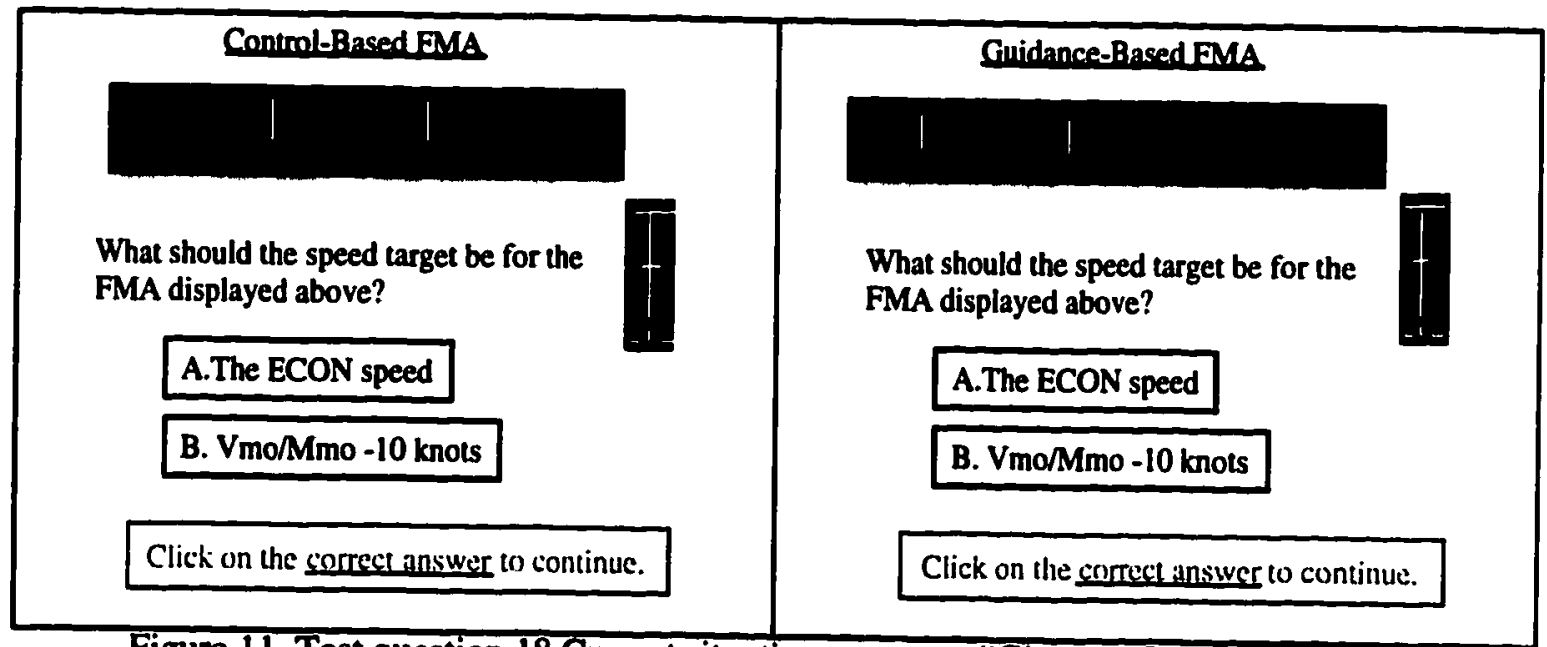

Figure 11. Test question 18 Current situation category: "Given an FMA, select the present situation description." 


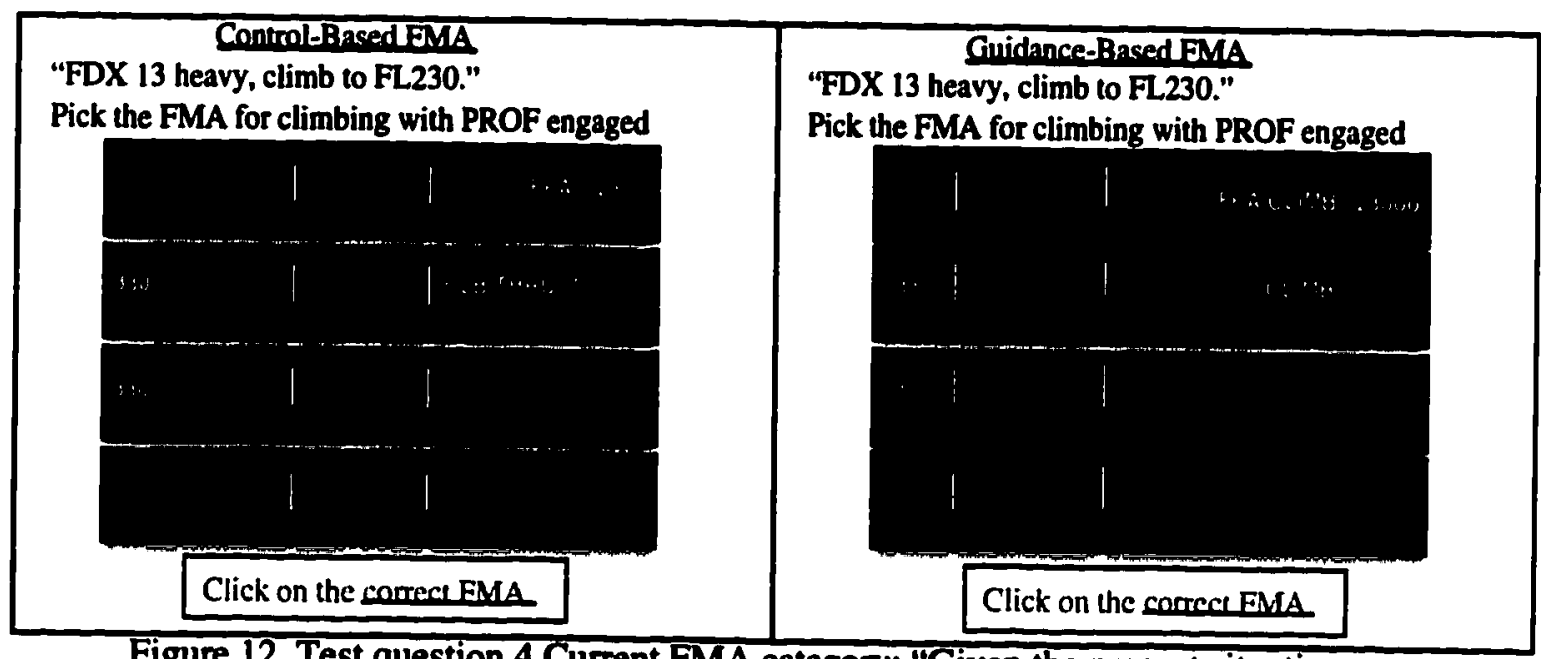

Figure 12. Test question 4 Current FMA category: "Given the present situation, select an FMA." 


\begin{tabular}{|c|c|}
\hline $\begin{array}{l}\text { Control-Based EMA } \\
\text { Given the FMA above, and the airplane is at } 335 \text { knots, } \\
\text { what will happen if the speedbrakes are extended? }\end{array}$ & $\begin{array}{l}\text { Given the FMA above, and the airplane is at } 335 \text { knots, } \\
\text { what will happen if the speedbrakes are extended? }\end{array}$ \\
\hline A. The aircraft will slow down. & A. The aircraft will slow down. \\
\hline B. The rate of descent will increase. & B. The rate of descent will increase. \\
\hline C. The autothrottles will increase thrust. & C. The autothrottles will increase thrust. \\
\hline Click on the correct answer to continue. & Click on the sorrect muswer to continue. \\
\hline
\end{tabular}

Figure 13. Test question 16. Situation Prediction category: "Given an FMA, select a future situation." 


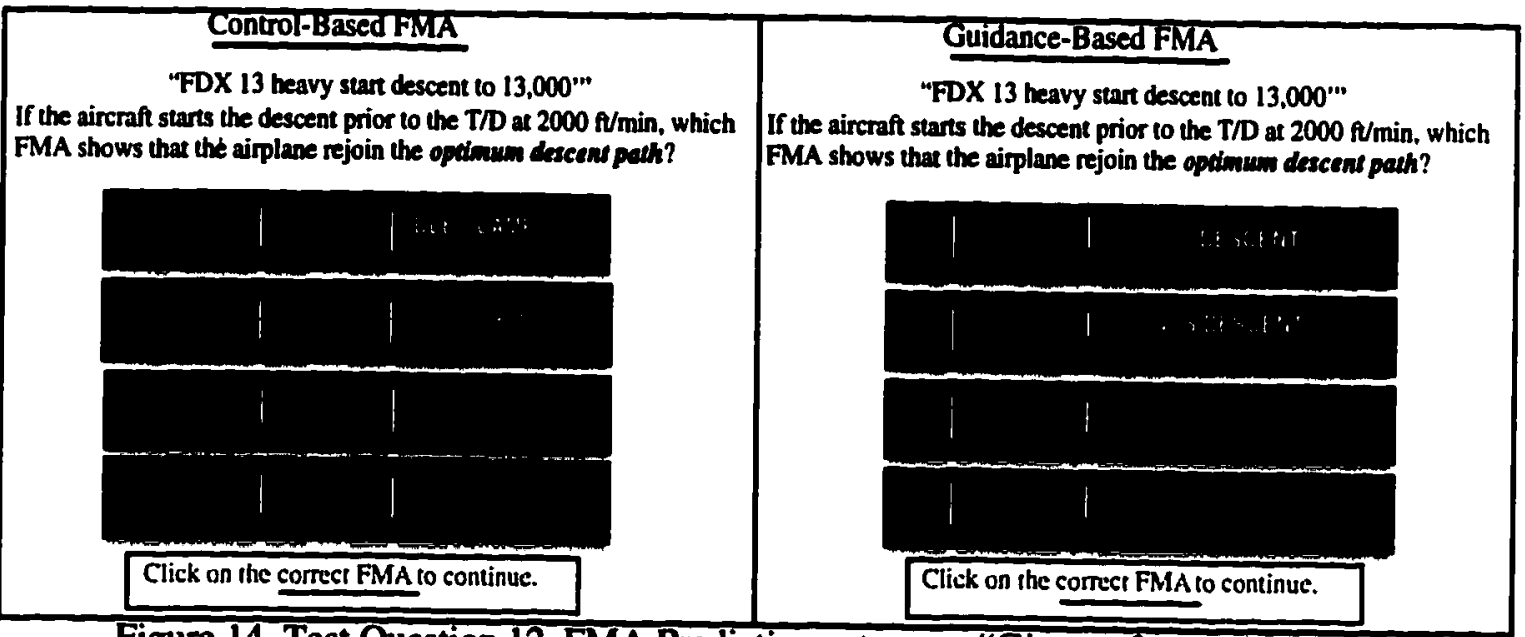

Figure 14. Test Question 12. FMA Prediction category: "Given a future situation, select an FMA." 
Guidance-Based FMA conditions. The performance on the two display conditions was measured with a 20 question test. This test had four types of questions resulting from the factorial combination of two levels of two response variables. The first response variable was presentation order. Half of the test questions presented an FMA and asked the participants to choose the correct situation description. The remaining half, described a flight situation and asked for the correct FMA. The second response variable was temporal status. Half of the these test questions asked for a description or FMA for the current situation; the other half asked about the next situation. Statistical analyses consisted of evaluating the training effectiveness as a consequence of these three variables: A 2 (display condition: Control-Based vs. Guidance Based FMA) x 2 (presentation order: FMA selection vs. situation selection) $\times 2$ (temporal status: current vs. future) mixed Analysis of Variance was conducted on pilot responses to the 20 questions from the test module. Condition was a between-subjects factor.

There was no main effect of display condition $[\mathbb{E}(1,32)=1.986, p=.168]$. However, there was a significant main effect for presentation order $[E(1,32)=25.412, \mathrm{D}<.0001]$. The condition for which the FMA was presented first and then required the selection of the correct situation resulted in better performance $(M=89 \%)$, than the questions for which the situation was presented first $(M=75 \%)$. There was also an unexpected main effect of temporal status $[E(1,32)=5.862, \mathbb{R}<.05]$. The questions which required a prediction $(M=86 \%)$ resulted in better performance than questions asking about the current situation $(\mathbf{M}=77 \%)$.

Finally, and perhaps most importantly, there was an interaction between the display condition and the presentation order of the question $[E(1,32)=4.1, \mathbb{R}<.05]$. As shown in Figure 15, the Guidance-Based FMA training condition resulted in significantly better performance than the Control-Based FMA training condition for test questions in which the situation was presented first. Figure 15 also shows that the two display conditions did not 


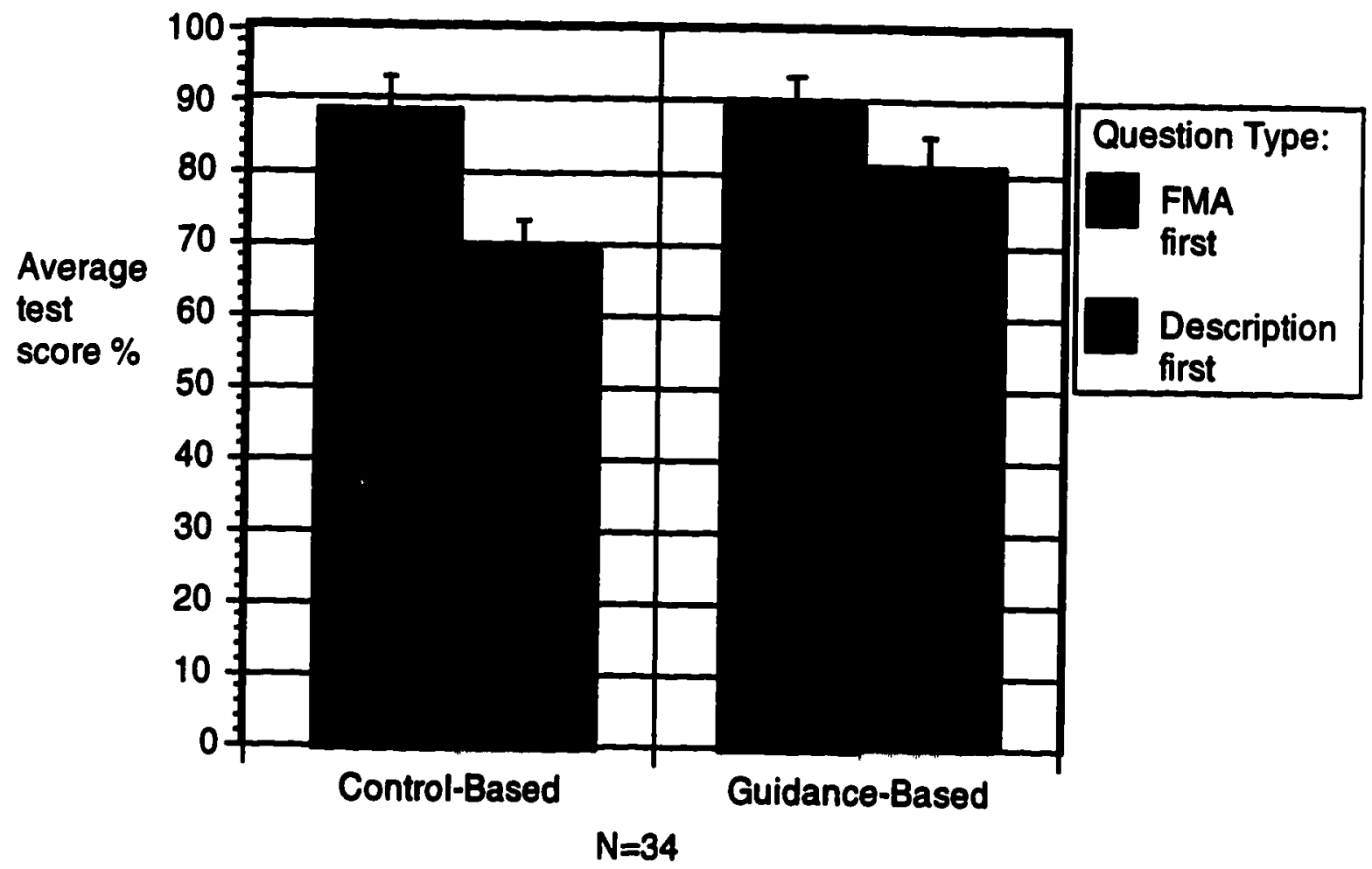

Figure 15. Two way interaction between question type and FMA condition 
show significant differences in performance for test questions in which the FMA was presented first.

To better describe this interaction, individual one-way Analyses of Variance were conducted on all 20 questions as a function of FMA condition (Control-Based vs.

Guidance-Based FMA). There were only two questions for which there was a statistically significant difference, question $4[E(1,32)=56.63, p<.001]$ and question 15

$[E(1,32)=190.06, \mathbb{p}<.01]$. The most interesting finding related to these individual question analyses is that these two questions (4 and 15) for which the Guidance-Based FMA group performed better than the Control-Based FMA group both belong to the same category, requiring selection of the correct FMA for the current situation.

\section{Discussion}

There were two important findings in this experiment. The first of these was the significant main effect of the presentation order of the two different types of questions. The first type of question presented a situation description and asked the participants select an FMA. This proved to be more difficult than the type of question for which an FMA was presented and the participants were asked to pick a description.

The second finding was related to the first, showing that for the type of question for which an FMA is selected from a set of alternatives, the Guidance FMA results in better performance. The concept of "label-following" is a possible explanation for the second finding.

\section{Question Type}

The first finding showed that it was more difficult for participants to select an FMA than to select a description of a guidance behavior. There are a number of possible explanations for this. First, of the 20 test questions, 10 of the 11 requiring the participants to select a correct description for a situation had at least one additional piece of information presented with the text description of the situation. An example of an additional piece of 
information can be seen in Figure 10, with the addition of the Vertical Deviation Indicator (below and to the left of the FMA). Other examples of additional information consisted of pictures of the Glareshield Control Panel (GCP), the Multifunction Control Display Unit (MCDU), and diagrams of the vertical situation of the aircraft. Only four of the nine test questions which required the participants to select the correct FMA gave one of these additional pieces of information. This additional information was necessary to answer the questions, but it is possible that the extra information may have biased those questions.

Secondly, the type of judgment required by the pilot may have been different for the two types of questions. The questions which required the selection of an FMA were fairly straightforward, with knowledge of the different anunciations as the only requirement. The questions which required the selection of an accurate description of the flight situation may have required the use of knowledge gained from a pilot's previous experience. Since the annunciations and behaviors should make sense to the pilot, it was hoped that a pilot could deduce the correct annunciation, but this may have worked in favor of questions which asked a pilot to choose a description of the situation. Figure 11 and Figure 12 also show a possible difference in the type of knowledge required to answer a question. Figure 11 shows a question that requires inference about the aircraft, while Figure 12 shows a question about a vertical guidance behavior.

Another possible explanation is that selecting a situation when given a display is closer to the actual task in flight. The DC-10 pilots who participated in this study do use an FMA on their airplane, and although it is different than the FMA used on the MD-11, the skill of reading a display and translating it to the aircraft situation may transfer to new displays. Annunciation Differences

The second finding indicated that the Guidance-Based FMA performs better for the more difficult type of question. A design goal of the Guidance-Based FMA was annunciations that are integrated and FMA labels which are operationally meaningful. The 
Climb example mentioned earlier illustrates this point. There is a more direct match between the task, in the form of a clearance which is given as "....Climb to FL330", and the behavior, "CLIMB" represented on the FMA display.

\section{Label-Following Heuristic}

Engelbeck (1986) identified the label-following heuristic. This heuristic refers to a strategy for learning to use a computer application in which the user attempts to find a menu label that matches his/her immediate goal. Polson and Lewis (1990) provide an example of the label following heuristic for a desktop software application. Participants were given a set of tasks, one of which was to "Center the text..." within a document. This was the only task for which the label of a menu item, "center" exactly matched the label used to describe the task. The difference in performance for these tasks was dramatic, over $90 \%$ of the participants made the correct selection on the first try for the label-following task. The other tasks had a very high error rate.

The label-following heuristic proposes that people find it easy to make selections in which the label of a response matches the task description they were given. The labelfollowing heuristic provides an explanation for the results observed on test question 4 (Figure 11). Test question 4 asked participants to select the FMA which matched the description: "CLIMB with PROF engaged". This is an accurate phrasing of the question, because the word PROF refers to the most automated configuration of the vertical guidance and is differentiated on the FMA by magenta versus white FMA text. The label following concept suggests that participants are likely to incorrectly select the FMA for PROF DESCENT, which has as its FMA annunciation the letters "PROF". Examination of the data supports this idea, as all of the participants who responded to this question incorrectly (12 of 17) selected the "PROF" annunciation first.

It should be noted that the questions were worded specifically to avoid biasing the performance of the Guidance FMA with the label-following heuristic. It is possible that the 
Guidance-Based FMA would show another performance improvement if the annunciations matched Air Traffic Control phraseology exactly. The Guidance-Based FMA does match Air Traffic Control phraseology in many cases, but there are some vertical guidance behaviors for which there are no corresponding Air Traffic Control terms.

\section{Training Material Development}

The experimental results may be partially explained by the type of training used. This study evaluated the performance of the Control-Based and Guidance-Based FMAs in learning declarative knowledge. Since the training had to be developed for both groups, the same conceptual model was used for both the Control-Based and Guidance-Based displays. It is possible that the use of the Guidance-Based conceptual model for training is more powerful than the effect of the different displays alone. It is possible that once a student recognizes the different behaviors that are possible in the automation, the transformation to different displays does not make much of a difference in performance. Summary

This paper described an experiment which tested the training effectiveness of a new display for automated vertical guidance. The displays and training developed for the experiment were designed to improve the recognition and understanding of the "objectives and behaviors" of automated systems through a formal methodology, referred to as the Operational Procedures Methodology (Sherry, 1995; Sherry et al., 1995; Sherry et al., 1997). The Operational Procedure Methodology utilizes the input of the designers as rule based logic to form the foundation for the concepts that need to trained. The experiment developed a training package designed to teach the vertical guidance portion of the Flight Mode Annunciator (FMA) display observed in normal automated operations of the MD-11. The results of the experiment showed that the Guidance-Based FMA showed significant improvements over the Control-Based FMA in some situations. 


\section{Ongoing Work}

The next step in this project has evaluated the Guidance-Based FMA in a full-mission MD-11 simulator. As part of a larger project, the Guidance-Based FMA has been built to run on actual flight hardware. A simulator study has been conducted using MD-11 pilots who have at least one year experience on the airplane. The participants were given one of the two training packages that were developed in the current study. The objective of the simulator study was to evaluate pilots' ability to understand the behavior of the vertical guidance system.

The results of the simulator study showed that for some tasks pilots were able to describe and predict the vertical guidance behavior of the aircraft more accurately with the Guidance-Based FMA. The data from the simulator study will be analyzed further to evaluate the usefulness of a Guidance-Based FMA in the operational environment.

There are additional areas that should be explored. First, a reaction time measure may provide a more sensitive measure of performance in the amount of time needed for recognition and understanding with the Guidance-Based FMA. Second, a goal in training the system should be "better retention over long periods of time," suggesting a longitudinal type evaluation. It would be interesting to take the volunteers in this study and evaluate them using the test questions without the training material, to test retention sometime in the future. 
References

Ellis, S. R., \& Hitchcock, R. J. (1986). The emergence of Zipf's law: Spontaneous encoding optimization by users of a command language. IEEE Transactions on Systems, Man, and Cybernetics, SMC.16 (3), 423-427.

Engelbeck, G. E. (1986). Exceptions to generalizations: Implications for formal models of human-computer interaction. Masters thesis, Department of Psychology, University of Colorado, Boulder, $\mathrm{CO}$.

FAA (1996). Federal Aviation Administration human factors team report on: The interfaces between flight crews and modern flight deck systems. Washington, D. C.

Hutchins, E. L. (1996). The Integrated mode management interface. (NASA Contractor Report), Moffett Field, CA: NASA Ames Research Center. Manuscript in preparation.

Polson, P. G., \& Lewis, C. H. (1990). Theory based design for easily leamed interfaces. Human Computer Interaction, 5, 191-220.

Sarter, N. R., \& Woods, D. D. (1993). Cognitive engineering in aerospace application: Pilot interaction with cockpit automation. (NASA Contractor Report 177617). Moffett Field, CA: NASA Ames Research Center.

Sherry, L. (1995). A formalism for the specification of operationally embedded reactive systems. In Proceedings Intemational Council of System Engineering, St. Louis, MO.

Sherry, L., Youssefi, D., \& Hynes, C. S. (1995). A formalism for the specification of operationally embedded reactive avionics systems. (Honeywell publication no. C695350-001). Phoenix, AZ.

Sherry, L., Kelley, J., McCrobie, D., Polson, P. G., Feary, M., Hynes, C. S., \& Palmer, E. A. (1997). A framework for the design of intentional systems in support of cooperative human-machine systems. In R. S. Jensen (Chair), Proceedings of the Ninth International Aviation Psychology Symposium Conference, Columbus, $\mathrm{OH}$ : The Ohio State University. 


\section{Appendix A \\ Experiment Introduction Sheet}

\section{Introduction to the FMA Tutor}

Thank you for volunteering to test our FMA Tutor training device. The FMA (Flight Mode Annunciator) is a display to summarize the behavior of the auto flight system of an aircraft like the MD-11. In our project, we are attempting to develop a tool to train pilots how to interpret the indications of the FMA, and translate those indications into situational awareness of where the automation is going.

This is a conceptual training device. We are evaluating the feasibility of and Internet-based computerized training device that will be available on your home computer, regardless of type, as long as it can support an Internet browser.

Prior knowledge of the MD-11 is not necessary, but please note the functions of the other devices (Glareshield Control Panel, Multifunction Control Display Unit, etc.) as their interaction is important to understanding the FMA.

This tutor will only cover commonly used modes encountered in normal operations, and will not cover abnormals, takeoffs, approaches or landings at this time.

This tutor is not an FAA approved training device, and is to be used solely for evaluating the effectiveness of such a device as well as the new prototype FMA displays.

Please take a few minutes to complete the questionnaire when you complete the training. It will help us to determine if this type of training could be valuable to you in the future.

Thank you for your cooperation 
Appendix B: Human Subjects Approval Form

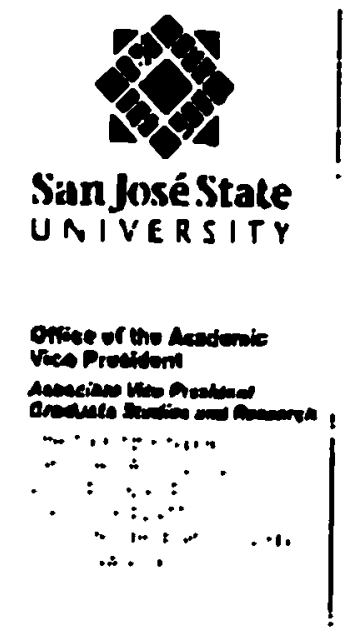

TO:

$$
\begin{aligned}
& \text { Mlonael Peary } \\
& 3703 \text { Poinciana Cr. } 35 \\
& \text { sanea clara, ca gsosi }
\end{aligned}
$$

MRon:

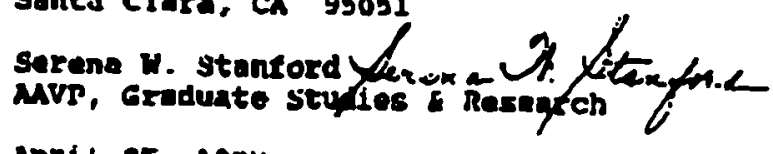

DATR:

Aprif 25, 199\%

The Human subjecem-Inatitutional Review Board has approved your requedt to use buman aubjects in tho seudy entitled:

\section{"Traluation of an Intentional Fllaht rode Aniunciation for the Training of verelcil Guidanea Logie"}

This approval is contingent upon tho subjecte participating in your researn project bing appropriately protectod from riek. This inciude the protection of the anomyatey of the subjects' idantiey when they parelelpate in your research projece, and with regard to any and all date thot bay be collected fron the subjects. The board's approvel includes continued wonitoring of your research by the board to assure that the sub jects are being adequately and properly protected frov suen rlsks. If at any ties i subject becomas injured of complains of injury, you nuse notify serona stanford. Eh.0. i inaedintely. In jury includes but in not ímiled to bodily harm, poychological trauma and release of potontially danaging permonal intormation.

Please also be advised that all eubjects noed to bu fully informad and aware thut their participation in your research protert is voluntary, and that ho or she nay vithurev from tho project at any tine. Turther, a subject's participation, refusal to parefcipate, or withdrawal will not affect any services the subject in receiving or wi2l receive at the institution in which the remeareh is boing
cenduated.

If you have any questions, please contunt ne at (408) $924-2480$.

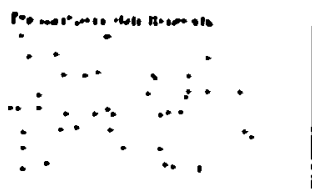

